\title{
Analysis of variables of the nutrition index alcohol and medicament use and post-traumatic stress disorder
}

\author{
Sarač-Hadžihalilović Aida1*, Rakanović-Todić Maida², Ajanović Zurifa1', Šljuka Senad³, \\ Dervišević Amela ${ }^{4}$
}

${ }^{1}$ Department of Anatomy, Faculty of Medicine, University of Sarajevo, Sarajevo, Bosnia and Herzegovina, ${ }^{2}$ Department of Pharmacology, Faculty of Medicine, University of Sarajevo, Sarajevo, Bosnia and Herzegovina, ${ }^{3}$ Department of Biology, Faculty of Science, University of Sarajevo, Sarajevo, Bosnia and Herzegovina, ${ }^{4}$ Department of Human Physiology, Faculty of Medicine, University of Sarajevo, Sarajevo, Bosnia and Herzegovina

\begin{abstract}
Introduction: The main aim of the study was to examine the interdependence of values of the nutrition index, the use of medicaments, and alcohol consumption in the group of subjects with post-traumatic stress disorder (PTSD) and in control group without PTSD.
\end{abstract}

Methods: To determine the interdependence of different indices of nutrition and the alcohol and drug consumption in both groups, the crosstab model was used.

Results: In both of the tested groups, medicament users had higher average values for nutritional indexes compared to the subjects that are not the consumers of medicaments, but the confirmed differences were not statistically significant. The subjects with PTSD who consume alcohol had lower average values for nutritional indexes compared to the subjects who do not consume alcohol. In the control group, subjects who consumed alcohol had higher mean values for nutritional indexes than those who did not consume alcohol. Differences in the values of the nutrition index between alcohol and non-alcohol subjects were not statistically significant either in the PTSD group or in the control group. The subjects with PTSD had less average values of all the used nutrition indexes compared to the control group subjects, but the confirmed differences were not statistically significant.

Conclusion: Our results indicate that medicaments use and alcohol consumption do not exert a statistically significant effect on the values of the nutrition index in any of the study groups. Possible concomitant use of drugs with the opposite effect on the monitored parameter (nitrazepam and amitriptyline vs. SSRI and bupropion) can lead to findings like this. We recommend further research to eliminate influence of pharmacodynamic effects of alcohol, drugs, and stress on the development of weight gain or loss.

Key words: Nutrition index; alcohol; medicaments; post-traumatic stress disorder

*Corresponding author: Sarač-Hadžihalilović Aida, Department of Anatomy, Faculty of Medicine, University of Sarajevo, Čekaluša 90, 71000 Sarajevo, Bosnia and Herzegovina.

E-mail: aida024@bih.net.ba

Submitted: 21 March 2019/Accepted: 25 April 2019

DOI: https://doi.org/10.17532/jhsci.2019.683

UNIVERSITY OF SARAJEVO FACULTY OF HEALTH STUDIES

\section{INTRODUCTION}

The main focus of the study is the interdependence of the values of the nutrition index, medicaments use, and alcohol consumption. The inclusion of stress and its role in the increase of overweight people in combination with the alcohol and medicament 
consumption, additionally complicate the analysis of the nutrition index and correct interpretation.

Literature data suggest the influence of consummation of alcohol and certain medicaments, along with stress, on weight gain (1-5). Some case studies refer to theories that characterize increased food consumption as addictive behavior, which was earlier the exclusivity for alcohol addiction (6). The answer to the question of whether the increased food consumption can be conceived as a dependent behavior is probably found in neurobiological studies that treat similarities between food consumption and the use of narcotics (6). A recent study about the relationship between eating, overeating, and addiction has found that obese patients have lower rates of alcohol use than was is found in the general population of women (1).

Furthermore, the results of numerous epidemiological studies have confirmed the correlation between alcohol use and obesity in women and pointed out the likely existence of this correlation in men. This interaction is explained by the possible impact of various factors including socio-demographic factors of the environment and predisposition for the development of alcoholism and related addiction disorders (2).

The increase in the obesity rate in the United States (USA) is not only a consequence of an increase in the population. Increased body mass index (BMI) values are due to environmental factors that affect the daily life of individuals, such as higher availability of low-cost and high-calorie food $(7,8)$. Research has shown that, however, certain subgroups of individuals are more liable to the variable surrounding factors.

The source and factors of general constitutional variation are both exogenous and endogenous nature. Among the exogenous determinants dominant influence of environmental, nutritional, and health and hygiene factors, and the interior are the most important genetic, biochemical, and physiological factors. Nutrition (obesity), as one of the most important determinants of body shape and obesity (as its very striking category), attracts particular scientific and general attention. The methods of assessing the biophysical constitution of the human body are very heterogeneous, inconsistent, and of limited applicability. Exact indicators of morphological-anatomical structure, shape and general habitat of the somatotype are determined according to different theoretical assumptions, patterns and their empirical corrections. Some of them are the Pignet pattern of body constitution, Broca normal BMI, Günter body shape index, Ketle's nutrition index, and Rorer's nutrition index (9).

The aim of our research is to further explore if the use of alcohol and medicaments could influence weight in post-traumatic stress disorder (PTSD) patients, measured by application of multiple nutrition indexes. Available research in the literature focuses on the impact of particular factors on the development of obesity. In our study, we also wanted to capture the impact of alcohol and medicaments use in patients with PTSD, given the implied significant role of stress. What gives a new dimension to those relationships is the application of different models in calculating the nutrition index (Demel's nutrition index SOO-calculated according to the standard general form, Ketle's nutrition index, BMI, and Rorer's nutrition index).

\section{METHODS}

\section{Study design}

The study included 78 male subjects, veterans, members of the B\&H Army. In the group of subjects with PTSD, there were 44 subjects, while the control group consisted of 34 subjects without PTSD. The PTSD group was examined at the Clinical Center University of Sarajevo at the Psychiatric Clinic - Department for PTSD, as well as the centers for Mental Health of Public Institutions of the Health Center of the Sarajevo Canton. Participants who were not diagnosed with PTSD (control group) were examined at ambulances within the Center for Occupational Health in Sarajevo during the period October 2004-November 2005.

\section{Study population}

Participants were selected according to the following inclusion and exclusion criteria. To achieve homogeneity of the participants' groups, only male persons and exclusively war veterans were included in PTSD and control group. One of the criteria for selecting patients with PTSD is the length of time the 
symptoms last. In our group, chronic PTSD comes into play. Besides, subjects were not included in the study (exclusion criteria) if they were younger than 18 years or older than 60 years of age (range: Min. 23-max. 59 years of age), had a head injury, or surgery during the traumatic experience. Furthermore, subjects with a history of neurological and psychotic diseases were not considered for participation. Selection the patient with PTSD was done with the Diagnostic and Statistical Manual - IV classification system published by American Psychiatrists Association in 1994. Participants in the control group were selected to be similar in age and education.

All individuals that satisfied inclusion and exclusion criteria between October 2004 and November 2005 were referred to Clinical Center University of Sarajevo at the Psychiatric Clinic - Department for PTSD, as well as the centers for Mental Health of Public Institutions of the Health Center of the Sarajevo Canton, were invited to participate in the study (with approximate response rate 99\%). All war veterans who first approached to ambulance within the Center for Occupation Health in Sarajevo during the period of collecting data were offered to participate in a study as a control group (response rate is $100 \%$ ). The same exclusion criteria were applied to the control group.

\section{Data collection}

Data were collected through face to face interviews (self-reported).

\section{Ethical considerations}

All participants participated in the study on a voluntary basis. Data are presented in a way that the identity of the participants cannot be recognized. All participants signed informed consent. This study was approved by the Ethics Committee of Medical Faculty University of Sarajevo.

Compared to the previously analyzed mainly qualitative characteristics of the subjects involved in the research, it is necessary to analyze the quantitative variables: Age, weight, and height. These variables are an integral part of the model for calculating the theoretical or desirable weight. Comparing the actual and theoretical weight, it is possible to calculate the appropriate nutrition index that is the focus of this research. These variables will be subject to further analyzes and comparisons between groups, and therefore at the very beginning, we will test whether they satisfy the assumption of normality for a complete sample without dividing the sample into groups. For all analyzed variables related to the nutrition index, $p$-value of the t-test is $>0.05$ which means that the difference between PTSD and control groups is not statistically significant.

Nutrition index was determined using:

- $\quad$ Standard general pattern: $\mathrm{I}=\mathrm{Ms} / \mathrm{Mt}$; where $\mathrm{Ms}$ - actual body weight $(\mathrm{kg})$ and $\mathrm{Mt}$ - theoretical body weight $(\mathrm{kg})$.

Estimated theoretical body weight could be determined using different calculation formulas:

a. $\operatorname{Mr}\left(\circlearrowleft^{\lambda}\right)=\mathrm{h}-100 ; \operatorname{Mt}(+)=\mathrm{h}-105 ; \mathrm{h}-$ height (cm); Broca

b. $\mathrm{Mt}=\mathrm{h}-100-(\mathrm{h}-150 / 4) ; \mathrm{h}-$ height $(\mathrm{cm})$; Azerad

c. Mt $=50+0.75 \times(\mathrm{h}-150), \mathrm{h}-$ height $(\mathrm{cm})$; American Insurance Company

d. $\operatorname{Mt}(\widehat{\jmath})=\mathrm{h}-100-\mathrm{h}-100 / 20 ; \operatorname{Mt}(+)=$ h-100-h-100/10

e. $\operatorname{Mr}(\circlearrowleft)=\mathrm{h}-100-\mathrm{h}-150 / 4+\mathrm{A}-20 / 4, \mathrm{Mt}($ ○) $=$ h-100-h-150/2,5+A-20/4, h - height (cm), A - age (year); Demolev's pattern.

- Ketle's nutrition index: $\mathrm{Q}=\mathrm{Ms} / \mathrm{h}^{2} ; \mathrm{Ms}-$ Actual body weight $(\mathrm{g})$; $\mathrm{h}$ - height $(\mathrm{cm})$

- $\quad$ BMI - Body mass index: BMI $=\mathrm{m} / \mathrm{h}^{2} ; \mathrm{m}-$ Actual body weight $(\mathrm{kg}) ; \mathrm{h}-$ Height $(\mathrm{m})$

- Rorer's nutrition index: $\mathrm{K}=100 \times \mathrm{m} / \mathrm{h}^{3} ; \mathrm{m}-$ Actual body weight (g); h - Height $(\mathrm{cm})$.

\section{Statistic analysis}

According to applied statistical methods for data analysis, our sample is large enough to offer significant results. Univariate statistics were applied to describe variability for quantitative variables. For testing differences between groups t-test for means were applied (normality assumption was fulfilled). We have some categorizations of the patients according to the different categorical variables, the analysis of the correlation between the individual categories of the nutrition index and the category according to categorical variables is done by the crosstabs, Chisquare test, and the measures of association. As all 
the included variables are numerical and normally distributed, for this analysis, we used a linear correlation and Pearson's linear correlation coefficient.

\section{RESULTS}

\section{Description of sample}

In both samples, only mail patients are included, so there are homogeneous samples according to gender structure.

According to the age structure, both groups of subjects are relatively heterogeneous (inside of each group) (Figure 1). The distribution of the population by age shows that in PTSD group, most of the subjects are in the fourth decade of life (54.6\%). In the control group, it is noticeable that we also have a significant proportion of patients aged up to 30 years $(23.5 \%)$, while such patients in the PTSD are far less $(6.8 \%)$. When we compare PTSD and control groups according to age (44.23 - average age in PTSP group and 38.35 average age in control group, $\mathrm{t}=3.269, p=0.002<0.05)$, we can conclude that there is a statistically significant difference between groups according to age.

The prevailing level of education of the subjects in both groups of subjects is secondary $(64.7 \%$ vs. $56.8 \%$ in control and PTSD group). Subjects with primary education in the control group were 23.5\% and in PTSD 43.2\%. There are no subjects with higher education levels in the PTSD group. In the control group, the prevalence of subjects with higher education levels is $11.8 \%$. The result of Chisquare test after crosstabulation of group and education level is Chi-square $=7.514$, Cramer V $=0.167$, and $p=0.0233<0.05$. We can conclude that there is a statistically significant difference between groups according to education level.

As expected, most of the subjects (90.9\%) in the PTSD group used pharmacotherapy. In the control group, the percentage of subjects who used pharmacotherapy was significantly lowers (29.4\%).

Figure 2 shows the distribution of different pharmacotherapy types ranked by frequency. The data regarding the distribution of the study participants according to alcohol and addictive substances consumption are similar between the two groups. None of the subjects were taking addictive substances. Sixteen (36.4\%) subjects of the PTSD group and $12(35.6 \%)$ subjects of the control group consumed alcohol.

The frequency distribution of the study participants for the independent variable alcohol consumption slightly differed between PTSD group and control group. There were treated alcoholics or addict groups

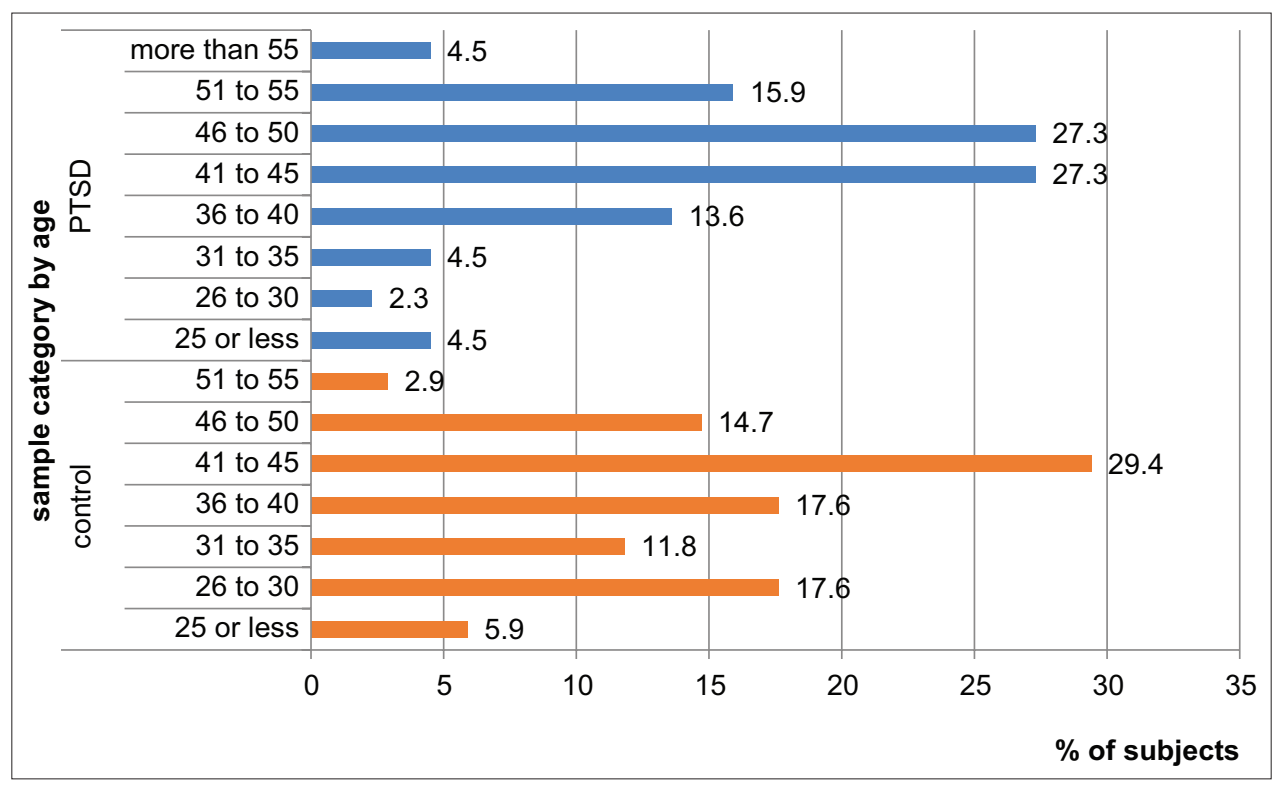

FIGURE 1. Structure of the sample according to age. 


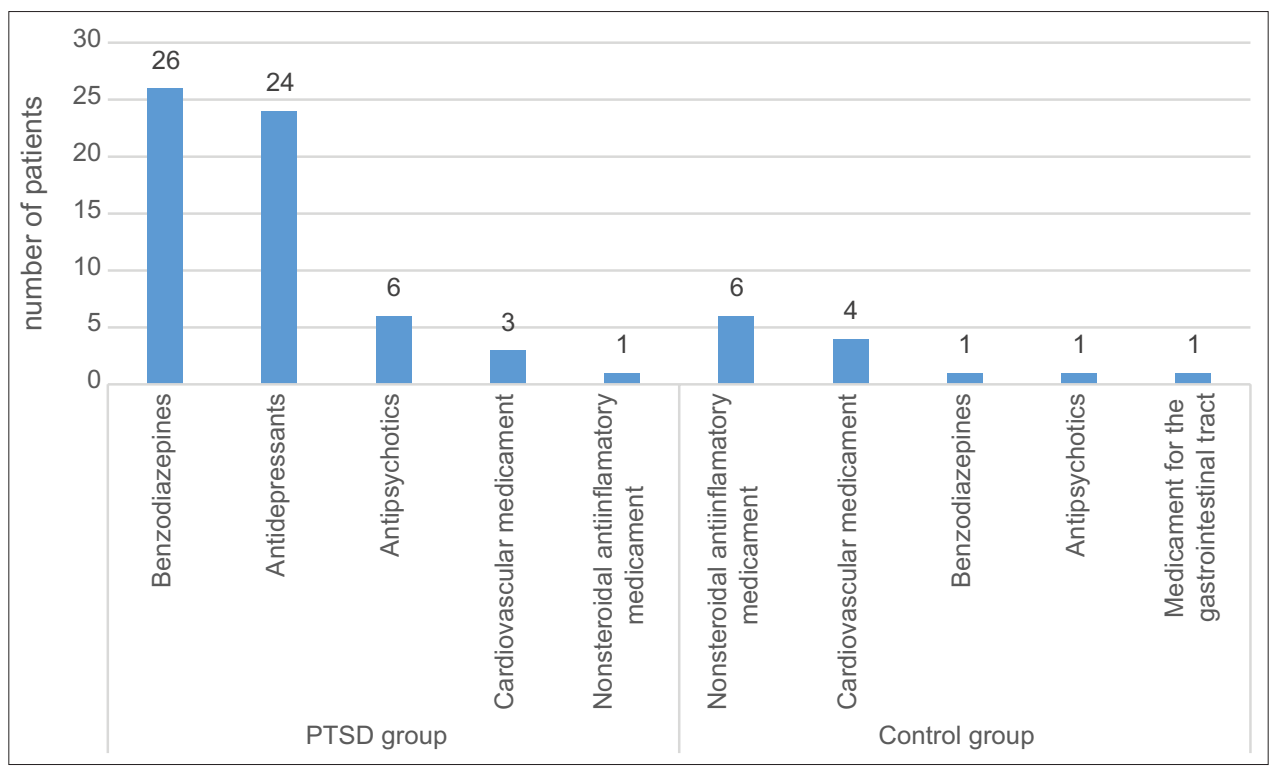

FIGURE 2. The distribution of different pharmacotherapy types ranked by frequency.

$(\mathrm{n}=2)$, as well as once a week drinkers $(\mathrm{n}=3)$ in PTSD group. Subjects of the control group were likely to be sometimes or daily drinkers (sometimes 7 vs. 5, daily 2 vs. 1 in control and PTSD groups). Distribution of rarely drinkers was the same in both groups $(\mathrm{n}=3)$.

\section{The comparison between PTSD and control groups}

The subjects with the PTSD had less average values of all tested nutrition indexes compared to the subjects of the control group, but the confirmed differences were not statistically significant (Figure 3 and 4).

For all analyzed variables related to the nutrition index, $p$-value of the t-test (normality assumption was fulfilled, Table 1) is greater than 0.05 which means that the difference between PTSD and control groups is not statistically significant (Table 2).

\section{Nutrition indexes and consumption of medicaments}

Regarding the consumption of medicaments, PTSD and control groups are divided into two subgroups: Medicament-consuming subjects and non-consuming subjects. We analyzed the existence of differences in mean values of the nutrition indexes between subgroups within the PTSD and the control group.
TABLE 1. The results of the Kolmogorov-Smirnov test for normality performed for the variables: Age, weight, and height

\begin{tabular}{lccc}
\hline Kolmogorov-Smirnov test & $\begin{array}{c}\text { Age } \\
\text { (years) }\end{array}$ & $\begin{array}{c}\text { Weight } \\
(\mathrm{kg})\end{array}$ & $\begin{array}{c}\text { Height } \\
(\mathrm{cm})\end{array}$ \\
\hline Mean & 41.67 & 84.97 & 178.54 \\
Standard deviation & 8.349 & 13.091 & 8.046 \\
Kolmogorov-Smirnov Z & 1.126 & 1.239 & 0.98 \\
p-value & 0.158 & 0.093 & 0.292 \\
\hline
\end{tabular}

Analyzing the existence of differences in mean values of the nutrition index between subgroups within the PTSD and the control groups, we determined that the subjects from the PTSD and control groups that consume medicaments had slightly higher average values of the nutrition index than non-consuming subjects (Table 3).

For all analyzed variables related to the nutrition index, the $p$-value of the t-test was greater than 0.05 , indicating that differences in the values of nutrition index among medicament-consuming and non-consuming subjects in both PTSD and control groups were not statistically significant and can be interpreted in the context of the fact that consumption of medicaments does not significantly affect the value of the nutrition index (Table 3). 


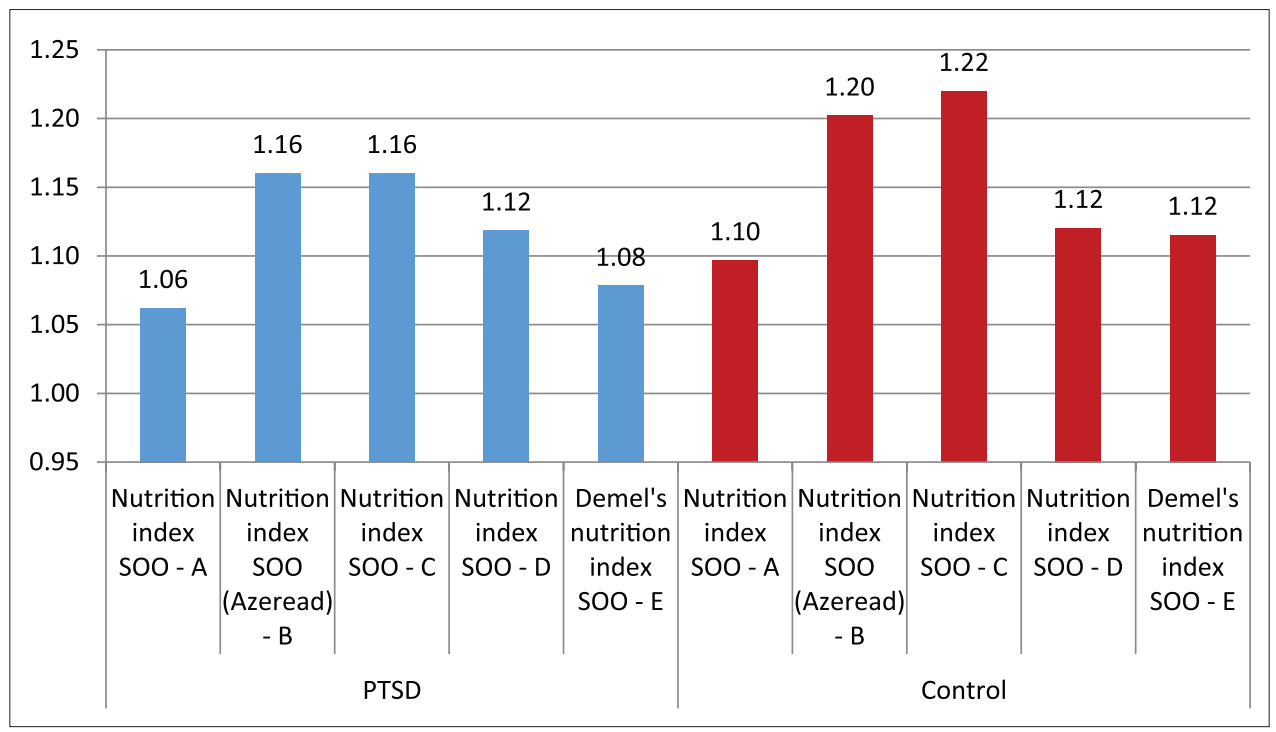

FIGURE 3. Average values for nutrition indexes $\mathrm{SOO}$ for different models for calculating the theoretical or desirable weight.

TABLE 2. Mean differences in variables related to nutrition indices between posttraumatic stress disorder and control group, according to the Student's t-test

\begin{tabular}{lcccccc}
\hline & \multicolumn{2}{c}{$\begin{array}{c}\mathrm{F} \text { test for equal } \\
\text { variances }\end{array}$} & & \multicolumn{2}{c}{$\begin{array}{c}\text { t-test for equal } \\
\text { means }\end{array}$} \\
\cline { 2 - 3 } \cline { 6 - 6 } & $\mathrm{F}$ & $p$-value & & $\mathrm{t}$ & $\mathrm{p}$-value \\
\hline Nutrition index SOO-A & 0.314 & 0.577 & & -1.074 & 0.286 \\
$\begin{array}{l}\text { Nutrition index SOO } \\
\text { (Azeread)-B }\end{array}$ & 1.170 & 0.283 & & -1.082 & 0.283 \\
Nutrition index SOO-C & 0.942 & 0.335 & & -1.708 & 0.092 \\
Nutrition index SOO-D & 0.571 & 0.452 & & -0.054 & 0.957 \\
Demel's-nutrition & 0.122 & 0.728 & & -1.154 & 0.252 \\
index SOO-E & & & & \\
Ketle's nutrition index & 0.997 & 0.321 & & -1.613 & 0.111 \\
BMI-nutrition index & 0.982 & 0.325 & & -1.619 & 0.110 \\
Rorer's nutrition index & 0.327 & 0.569 & & -0.455 & 0.650 \\
\hline
\end{tabular}

Taking into consideration that we have the categorization of the patients according to the values of different nutrition index, the analysis of the correlation between the individual categories of the nutrition index and the category according to the consumption of medicaments is done by the crosstabs, Chi-square test, and the measures of association.

Crosstab confirms the previous conclusion that there is no statistically significant association between the Demole's nutrition index and consumption of medications (PTSD group: Chi-square $=1.222$,
Cramer $\mathrm{V}=0.167$, and $p=0.543>0.05$; and control group: Chi-square $=1.117$, Cramer $\mathrm{V}=0.181$, and $p=0.574>0.05)$ that means the consumption of medications does not affect the category in which the value of the Demole's nutrition index for a particular subject will be included.

In this case also, crosstab confirms the previous conclusion that there is no statistically significant association between the Ketle's nutrition index and consumption of medications (PTSD group: Chi-square $=1.423$, Cramer $\mathrm{V}=0.180$, and $p=0.700>0.05$; and control group: Chi-square $=1.672$, Cramer $\mathrm{V}=0.222$, and $p=0.643>0.05$ ) that means the consumption of medications does not affect the category in which the value of the Ketle's nutrition index for a particular subject will be included.

Crosstab again confirms the previous conclusion that there is no statistically significant association between the BMI nutrition index and consumption of medications (PTSD group: Chi-square $=0.911$, Cramer $\mathrm{V}=0.144$, and $p=0.340>0.05$; and control group: Chi-square $=0.731$, Cramer $\mathrm{V}=0.147$, and $p=0.393>0.05)$ that means the consumption of medications does not affect the category in which the value of the BMI nutrition index for a particular subject will be included.

One more time, crosstab confirms the previous conclusion that there is no statistically significant association 


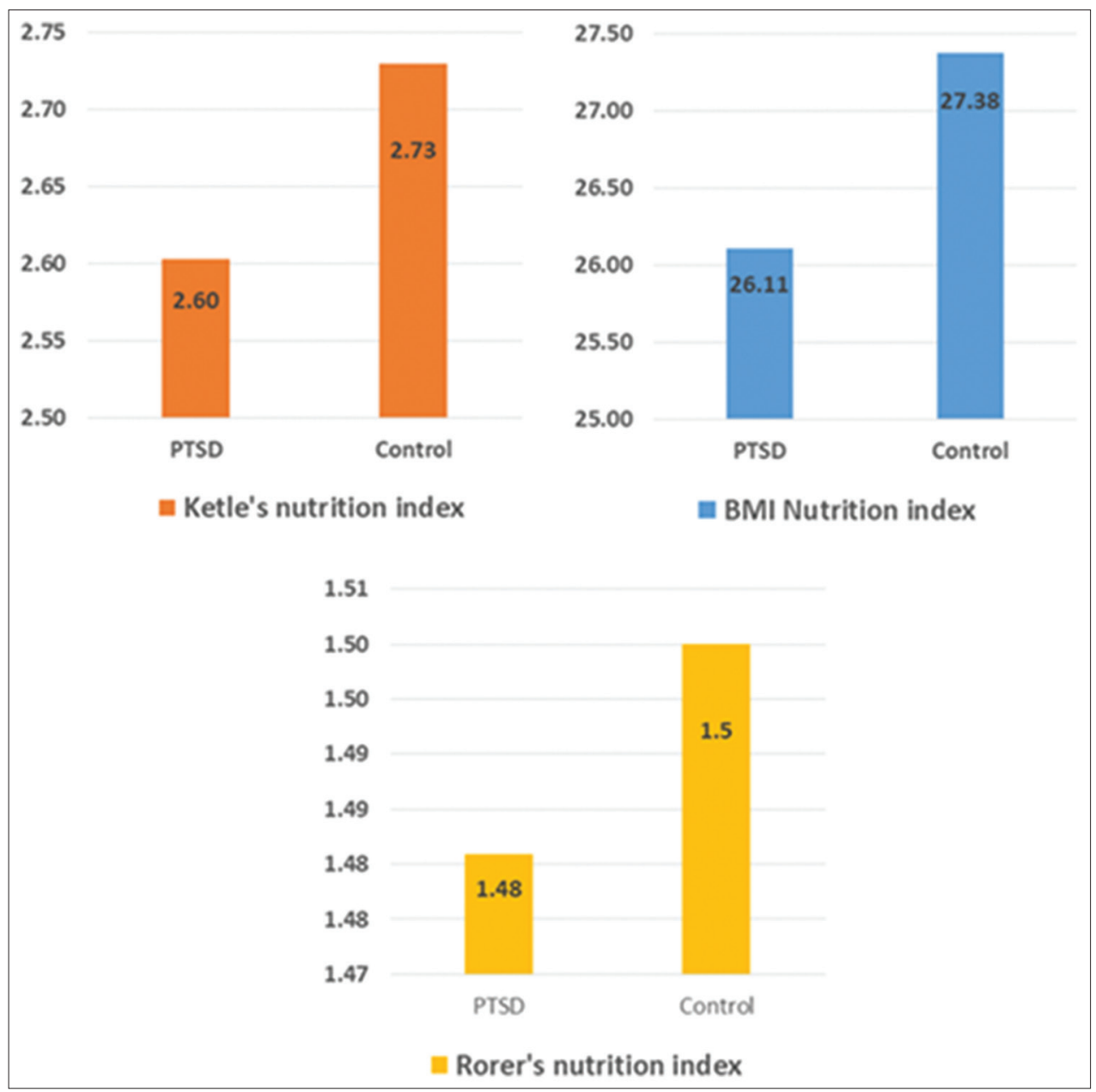

FIGURE 4. Average values for Ketle's nutrition index, body mass index nutrition index, and Rorer's nutrition index.

between the Rorer's nutrition index and consumption of medications (PTSD group: Chi-square $=0.390$, Cramer $\mathrm{V}=0.094$, and $p=0.823>0.05$; and control group: Chi-square $=0.464$, Cramer $\mathrm{V}=0.117$, and $p=0.793>0.05)$ that means the consumption of medications does not affect the category in which the value of the Rorer's nutrition index for a particular subject will be included.

\section{Nutrition indexes and consumption of medicaments in PTSD group}

An additional statistical analysis was done within a subgroup of patients who took antidepressants and/ or antipsychotics and subgroups of patients who did not take antidepressants and/or antipsychotics.
Of the 44 subjects in the PTSD, 40 of them consume medication. Of these, 27 take antidepressants and/or antipsychotics. The aim is to compare the subgroup of patients who consume antidepressants and/or antipsychotics with a subgroup of patients who do not consume antidepressants and/or antipsychotics within the PTSD group (Table 4).

In PTSD subgroups patients who do not take antidepressants and/or antipsychotics, the average values of the nutrition index are slightly lower. In the following table, we check whether these differences are significant, using the t-test for independent samples. For all the observed variables related to nutrition indexes, $p$-value of the t-test was more than 0.05 , which means that differences in PTSD patients 


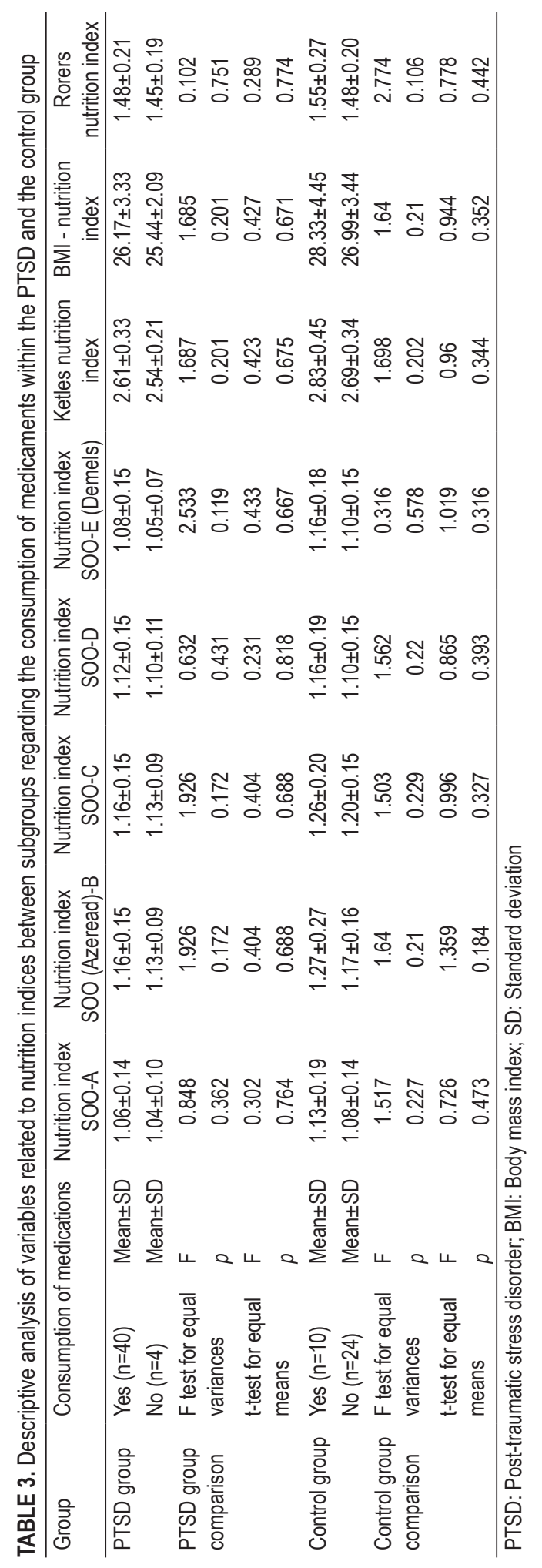




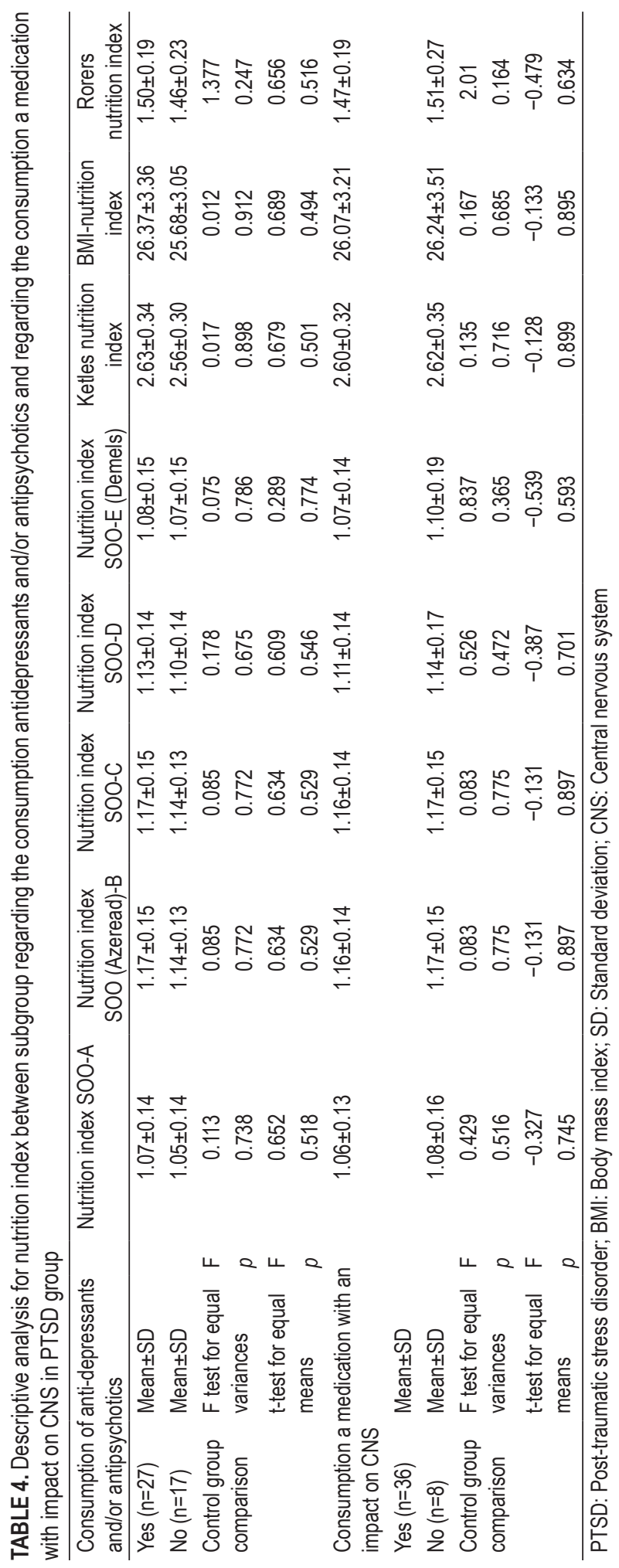


in the subgroups of patients who take or not take antidepressants and/or antipsychotics are not statistically significant (Table 4).

Additional analyses were made in the subgroup of patients who consume medication with an impact on the central nervous system (CNS) (antidepressants, antipsychotics, and/or anxiolytics) and a subgroup of patients who do not consume medication with an impact on CNS.

From 44 subjects in the PTSD, 40 of them take medication. Of these, 36 consume medication with an impact on CNS.

In PTSD subgroups, patients who do not consume medication with an impact on CNS have a little bit higher nutrition index (Table 4). To make sure of this slight difference, we will formally test this in the following table whether these differences are significant, using the t-test for independent samples.

As expected, for all observed variables related to nutrition indexes, a $p$-value of the t-test is more than 0.05, which means that the differences in PTSD subgroups patients who consume and do not consume medication with an impact on CNS patients are not statistically significant (Table 4).

\section{Nutrition indexes and consumption of alcohol}

In the PTSD group, subjects that consume alcohol have lower average value for the nutrition index compared to the subjects that do not consume alcohol. In the control group, subjects that consume alcohol have more average values than the subjects that do not consume alcohol (Table 5).

Whether the differences are significant is checked using the t-test for independent samples.

Taking into consideration that for all analyzed variables that are related to the nutrition index, $p$-value of the t-test was greater than 0.05 , the determined differences between alcohol-consuming subjects and subjects who do not consume alcohol in the PTSD and the control group were not statistically significant. These results can be interpreted also in the context that alcohol consumption does not affect significantly the value of the nutrition index (Table 5).

Taking into consideration that we have the categorization of the patients according to the values of different nutrition index, the analysis of the correlation between the individual categories of the nutrition index and the category according to alcohol consumption is done by the crosstabs, Chisquare test, and the measures of association.

Crosstab confirms the previous finding that there is no statistically significant association between the Demel's nutrition index and alcohol consumption (PTSD group: Chi-square $=0.491$, Cramer $\mathrm{V}=0.106$, and $p=0.782>0.05$; and control group: Chi-square $=$ 1.462 , Cramer $V=0.207$, and $p=0.481>0.05$ ) that means the consumption of alcohol does not affect the category in which the value of the Demel's nutrition index for a particular subject will be included.

In this case, again crosstab confirms the previous finding that there is no statistically significant association between the Ketle's nutrition index and alcohol consumption (PTSD group: Chi-square $=3.363$, Cramer $\mathrm{V}=0.276$, and $p=0.339>0.05$; and control group: Chi-square $=1.174$, Cramer $\mathrm{V}=0.186$, and $p=0.759>0.05$ ) that means the consumption of alcohol does not affect the category in which the value of the Ketle's nutrition index for a particular subject will be included.

Crosstab confirms the previous finding that there is no statistically significant association between the BMI nutrition index and alcohol consumption (PTSD group: Chi-square $=0.052$, Cramer $\mathrm{V}=0.340$, and $p=0.820>0.05$; and control group: Chi-square $=0.471$, Cramer $\mathrm{V}=0.118$, and $p=0.493>0.05)$ that means the consumption of alcohol does not affect the category in which the value of the BMI nutrition index for a particular subject will be included.

Crosstab confirms the previous finding that there is no statistically significant association between the Rorer's nutrition index and alcohol consumption (PTSD group: Chi-square $=2.866$, Cramer $\mathrm{V}=0.255, p=0.239>0.05$; and control group: Chi-square $=1.011$, Cramer $\mathrm{V}=0.172$, and $p=0.603>0.05)$ that means the consumption of alcohol does not affect the category in which the value of the Rorer's nutrition index for a particular subject will be included.

\section{Nutrition indexes and age of patients}

We tested that there is a significant correlation between the different nutrition indexes and age of 


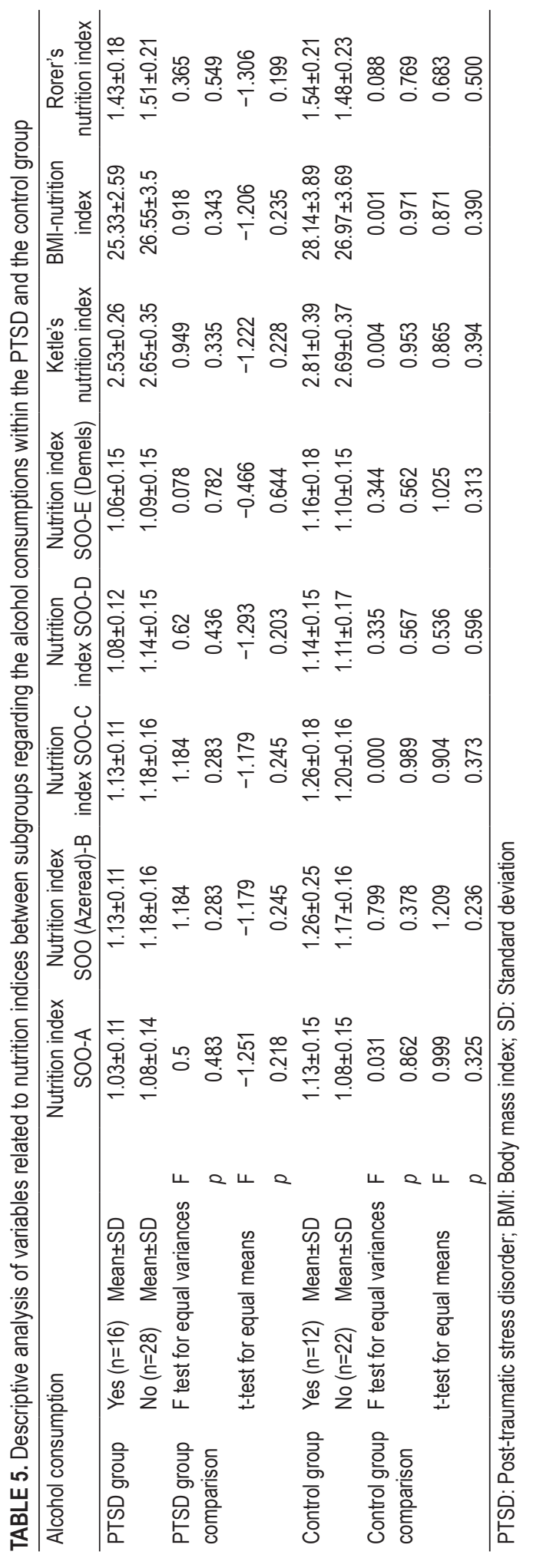


patients in both analyzed groups (PTSD and control group) (Table 6).

The correlation analysis in the PTSD group did not show a statistically significant relationship between the age of subjects and any nutrition index. In the control group, the correlation analysis showed a statistically significant relationship between the age of subjects and nutrition index SOO-D (40.5\%) and between the age of subjects and Rorer's nutrition index (39.9\%).

\section{DISCUSSION}

The study aims to examine the interdependence of values of the nutrition index, the use of the medicaments and alcohol consumption in the group of subjects with PTSD and in the control group of subjects without PTSD.

Subjects with PTSD had less average values of all tested nutrition indexes compared to the subjects of the control group, but this was not detected as statistically significant. Subjects that use medicaments both in the PTSD and in the control group had higher average values of the nutrition index compared to those who did not use medicaments. In PTSD subgroups patients who do not take antidepressants and/or antipsychotics, the average values of the nutrition index are slightly lower. In PTSD subgroups, patients who do not consume medication with an impact on CNS have a little bit higher average values of nutrition index. Subjects with the PTSD who consumed alcohol had lower average values, while the subjects in the control group who consumed alcohol had higher average values for nutritional indexes compared to the subjects who are not alcohol consumers. Our results indicate that medicaments use and alcohol consumption do not exert a statistically significant effect on the values of the nutrition index in any of the study groups.

The age of the subjects did not significantly correlate with none of the used nutrition indexes regarding the PTSD subjects, while the control group showed statistically significant correlations of age and nutrition index SOO-D (40.5\%) and Rorer's nutrition index (39.9\%).

Our result did not indicate a statistically significant effect of medicament use and alcohol consumption on the values of the nutrition index in any of the study groups.
TABLE 6. The correlation analysis between the age of subjects and different nutrition indexes

\begin{tabular}{|c|c|c|}
\hline & \multicolumn{2}{|c|}{ Age of subjects } \\
\hline & PTSD group & Control group \\
\hline \multicolumn{3}{|l|}{ Nutrition index SOO - A } \\
\hline $\begin{array}{l}\text { Pearson's linear correlation } \\
\text { coefficient }\end{array}$ & 0.023 & 0.327 \\
\hline$p$-value & 0.882 & 0.059 \\
\hline \multicolumn{3}{|l|}{$\begin{array}{l}\text { Nutrition index SOO } \\
\text { (Azeread)-B }\end{array}$} \\
\hline $\begin{array}{l}\text { Pearson's linear correlation } \\
\text { coefficient }\end{array}$ & 0.046 & 0.240 \\
\hline$p$-value & 0.767 & 0.171 \\
\hline \multicolumn{3}{|l|}{ Nutrition index SOO-C } \\
\hline $\begin{array}{l}\text { Pearson's linear correlation } \\
\text { coefficient }\end{array}$ & 0.046 & 0.293 \\
\hline$p$-value & 0.767 & 0.093 \\
\hline \multicolumn{3}{|l|}{ Nutrition index SOO-D } \\
\hline $\begin{array}{l}\text { Pearson's linear correlation } \\
\text { coefficient }\end{array}$ & 0.032 & $0.405^{\star}$ \\
\hline$p$-value & 0.838 & 0.018 \\
\hline \multicolumn{3}{|l|}{$\begin{array}{l}\text { Nutrition index SOO-E } \\
\text { (Demel's) }\end{array}$} \\
\hline $\begin{array}{l}\text { Pearson's linear correlation } \\
\text { coefficient }\end{array}$ & -0.130 & 0.171 \\
\hline$p$-value & 0.401 & 0.332 \\
\hline \multicolumn{3}{|l|}{ Ketle's nutrition index } \\
\hline $\begin{array}{l}\text { Pearson's linear correlation } \\
\text { coefficient }\end{array}$ & 0.041 & 0.314 \\
\hline$p$-value & 0.793 & 0.071 \\
\hline \multicolumn{3}{|l|}{ BMI - nutrition index } \\
\hline $\begin{array}{l}\text { Pearson's linear correlation } \\
\text { coefficient }\end{array}$ & 0.043 & 0.314 \\
\hline$p$-value & 0.782 & 0.071 \\
\hline \multicolumn{3}{|l|}{ Rorer's nutrition index } \\
\hline $\begin{array}{l}\text { Pearson's linear correlation } \\
\text { coefficient }\end{array}$ & 0.002 & $0.399^{*}$ \\
\hline$p$-value & 0.989 & 0.020 \\
\hline
\end{tabular}

PTSD: Post-traumatic stress disorder; BMl: Body mass index

A possible reason for this may be a comprehensive approach to the study design (including the stress component of PTSD, the impact of alcohol and medication, and the application of different nutrition index, or the characteristics of the partition population itself, since the study focuses on male war veterans).

Data from the literature indicate the following: The hypothalamus is recognized as the main region of 
the brain responsible for controlling the signals that regulate the intake of food (10).

Hormonal factors that modulate the activity of hypothalamus (leptin, ghrelin, and insulin) also have a conspicuous effect on the limbic regions of the brain that regulate food consumption through the brain reward system, motivation, learning, emotions, and stress reactions (11).

It is considered that when the stress reaction occurs, the so-called compulsive food consumption occurs as well. It is assumed that this reaction is a brain mechanism similar to that one, which ultimately leads to compulsive drug consumption in a state of addiction (12). Both the consumption of food and the use of drugs are encouraged by a sense of reward, but through various mechanisms which are associated with an increase of dopamine activity in the circle of rewarding the brain (13).

Food addiction can be a guideline for assessing the complexity of trauma, the complexity of PTSD and its symptoms, psychiatric comorbidity (8), level of overweight, and their interactions (14).

In the past years, there has been a significant scientific effort aimed at finding the structural and functional brain change, especially limbic system on PTSD that proves smaller hippocampal volume at war veterans with PTSD (15-17). Smaller hippocampal volume can be risk factor for development of especially and permanent form of PTSD (18).

The results of numerous psychiatric studies proved the correlation between antidepressants and increased or decreased body weight $(3,4,5,19)$. For PTSD subgroup, our results showed that patients who do not take antidepressants and/or antipsychotics had slightly lower average values of the nutrition indexes, while patients who do not consume medication with impact on CNS had a little bit higher average values of nutrition indexes. However, we noted that both of these findings are not statistically significant. Possible pharmacodynamic explanations of the potential impact on nutrition indexes are again a topic for future research, which we strongly recommend. It is not unknown if nitrazepam and amitriptyline affect the increase in body weight, while SSRI and bupropion are associated with weight loss $(3,4,5,19)$.

What is often ignored in the studies regarding the interdependence evaluation of multiple factors that interact with one another is also the application of different methodologies in evaluating the nutrition index $(20,21)$. This subject was considered within the applied medical anthropology, bioanthropology, anatomy, physiology, preventive medicine, and epidemiology (20). Therefore, it is recommended the use of the methodology for calculating the nutrition index according to the standard general form (SOO) - Demel's, Ketle's, BMI, and Rorer's nutrition index are recommended. The results of the previous research in this area indicated on higher correlation value of coefficients for the variables related to nutrition index, comparing the control group and the PTSD group (21).

\section{Limitations}

One of the limitations of our study derived from the self-reporting method of data collection (subjective to a bias of memory). Furthermore, the limitation is a significant difference between groups according to age and education level of participants; even they are not the crucial factor for weight gain and loss.

\section{CONCLUSION}

Our findings did not indicate a significant effect of medication and alcohol on nutrition index in war veterans with or without PTSD. It is an open question whether the characteristics of the participants are the most significant factor, considering the hippocamp is particularly sensibile to structural change caused by chronic stress.

Possible concomitant use of drugs with the opposite effect on the monitored parameter (nitrazepam and amitriptyline vs. SSRI and bupropion) can lead to findings like this. It is not unknown if nitrazepam and amitriptyline affect the increase in body weight, while SSRI and bupropion are associated with weight loss.

We recommend further research to ilimunate influence of pharmacodynamic effects of alcohol, drugs, and stress on the development of weight gain or loss.

\section{ACKNOWLEDGMENTS}

The authors would like to express their gratitude to Emina Resić, Professor at the Department of Quantitative Economics - Faculty of Economics 
and Business University of Sarajevo, Bosnia and Herzegovina for help with statistical analyses.

\section{CONFLICTS OF INTEREST}

The authors declare that they have no conflicts of interest.

\section{REFERENCES}

1. Kleiner KD, Gold MS, Frost-Pineda K, Lenz-Brunsman B, Perri MG, Jacobs WS. Body mass index and alcohol use. JAddict Dis 2004;23:105-18.

2. Grucza RA, Krueger RF, Racette SB, Norberg KE, Hipp PR, Bierut LJ. The emerging link between alcoholism risk and obesity in the United States. Arch Gen Psychiatry 2010;67:1301-8. https://doi.org/10.1001/archgenpsychiatry.2010.155.

3. Reekie J, Hosking SP, Prakash C, Kao KT, Juonala M, Sabin MA. The effect of antidepressants and antipsychotics on weight gain in children and adolescents. Obes Rev 2015;16:566-80.

https://doi.org/10.1111/obr.12284

4. Schwartz TL, Nihalani N, Virk S, Jindal S, Chilton M. Psychiatric medication-induced obesity: Treatment options. Obes Rev 2004;5:233-8.

https://doi.org/10.1111/j.1467-789x.2004.00149.x.

5. Cockerill RG, Biggs BK, Oesterle TS, Croarkin PE. Antidepressant use and body mass index change in overweight adolescents: $\mathrm{A}$ historical cohort study. Innov Clin Neurosci 2014;11:14-21.

6. Gearhardt AN, Corbin WR. Body mass index and alcohol consumption: Family history of alcoholism as a moderator. Psychol Addict Behav 2009;23:216-25.

https://doi.org/10.1037/a0015011.

7. Hill JO, Peters JC. Environmental contributions to the obesity epidemic. Science 1998;280:1371-4.

8. Jeffery RW, Utter J. The changing environment and population obesity in the United States. Obes Res 2003;11:12S-22.

https://doi.org/10.1038/oby.2003.221.

9. Hadziselimovic R. Bioantropologia. Rod Homo u prostoru i vremenu, Sarajevo: INGEB, Univerzitet u Sarajevu; 2018.
10. Volkow ND, O'Brein CP. Should obesity be included as a brain disorder? Am. J Psychiatry 2007;164:708-10.

11. Morton GJ, Cummings DE, Baskin DG, Barsh GS, Schwartz MW. Central nervous system control of food intake and body weight. Nature 2006;443:289-95.

https://doi.org/10.1038/nature05026.

12. Volkow ND, Wise RA. How can drug addiction help us understand obesity? Nat Neurosci 2005;8:555-60.

https://doi.org/10.1038/nn1452.

13. Wise RA, Rompre PP. Brain dopamine and reward. Annu Rev Psychol 1989;40:191-225

https://doi.org/10.1146/annurev.ps.40.020189.001203.

14. Brewerton TD. Food addiction as a proxy for eating disorder and obesity severity, trauma history, PTSD symptoms, and comorbidity. Eat Weight Disord 2017;22:241-7.

https://doi.org/10.1007/s40519-016-0355-8.

15. Pitman RK. Hippocampal diminution in PTSD: More (or less?) than meets the eye. Hippocampus 2001;11:73-4.

https://doi.org/10.1002/hipo.1022.

16. Bremner JD, Vermetten E. Neuroanatomical changes associated with pharmacotherapy in posttraumatic stress disorder. Ann N Y Acad Sci 2004;1032:154-7.

17. Sarac-Hadžihalilovic A. Dilberović F. Kucukalic A. Hippocampal volume in posttraumatic stress disorde. Dynam Psychiatry Int J Psychother Psychoanal Psychiatry 2008;41:102-13.

18. Bonne O, Brandes D, Gilboa A, Gomori JM, Shenton ME, Pitman RK, et al. Longitudinal MRI study of hippocampal volume in trauma survivors with PTSD. Am J Psychiatry 2001;158:1248-51.

https://doi.org/10.1176/appi.ajp.158.8.1248.

19. Serretti A, Mandelli L. Antidepressants and body weight: A comprehensive review and meta-analysis. J Clin Psychiatry 2010;71:1259-72. https://doi.org/10.4088/jcp.09r05346blu.

20. Sarac-Hadzihalilovic A, Elfaki A, Sljuka S, Aganovic-Musinovic A, Lujinovic A, Sahin B. Different calculation formulas for ideal body weight and actual/ideal body weight index estimation in post-traumatic stress disorder patients Folia Med Fac Med Univ Saraeviensis 2016;51:92-5.

21. Hadzihalilovic AS, Sljuka S, Ajanovic Z. Determining the direction of disagreement between Demel's standard general pattern of nutrition index; Ketle's; BMI and rorer's nutrition index. Balkan J Health Sci 2018;6:11-23. 